\title{
The Role of Physiotherapy in the Rehabilitation of Stroke Patients with Lower Urinary Tract Symptoms
}

\section{Sigrid Tibaek*}

\section{Department of Occupational Therapy and Physiotherapy, Rigshospitalet, University of Copenhagen, Denmark}

\begin{abstract}
Background: Lower urinary tract symptoms (LUTS) are highly prevalent in both male and female patients after stroke, ranging up to $94 \%$. Physiotherapy has been involved in treatment of LUTS in neurologically healthy patients for decades and, over the past few years, and mostly in research, in patients with neurological diseases.

Objective: The objective of this study is to describe how physiotherapy can be involved in the prevention, diagnostic and treatment during the rehabilitation of stroke patients with LUTS.

Summary: This study introduces basic evidence for LUTS in stroke patients. Identify factors and describe exercise interventions for prevention of LUTS. Followed by validated and reliable specific assessments indicated for physiotherapy, and present treatment programs of pelvic floor muscle at different levels for stroke patients.

Conclusion: It is recommended that physiotherapy can provide valuable contribution in the prevention, diagnostic and treatment during the rehabilitation of stroke patients with LUTS.
\end{abstract}

Keywords

Lower urinary tract symptoms, Physiotherapy, Rehabilitation, Stroke

\section{Introduction}

In developing countries with low and middle income the incidence of stroke increases by more than $100 \%$ $[1,2]$. Whereas, in countries with high income it has decreased due to lifestyle changes and new treatment approaches [1]. Globally, there is both an aging population with an increasing proportion of disabled people [3] and an increasing numbers of stroke survivors requiring rehabilitation services for acquired deficits such as motor disability, cognitive impairment, dysphasia, dysphagia and lower urinary tract symptoms (LUTS) [4-6].

The prevalence of LUTS in post-stroke patients ranges from $15 \%$ to $94 \%$, depending on time since stroke $[7,8]$. The most prevalent post-stroke LUTS are nocturia $(76 \%)$, followed by urgency $(70 \%)$ and increased daytime frequency (58\%) [7], but urinary incontinence (UI), incomplete bladder emptying [9] and urinary tract infection (UTI) are also prevalent [10]. In addition, several non-neurological LUTS with different causes are frequent in post-stroke patients, especially post micturition dribbling and hesitation in men, and stress urinary incontinence (SUI) in women. The International Conti- nence Society (ICS) has defined these symptoms $[4,5]$ as shown in Table 1.

LUTS have a significant impact on the quality of life (QoL) of stroke patients [7,11-14], caregivers and relatives [15]. It has been reported that $78 \%$ of post-stroke patients have LUTS-related problems in activities of daily living [7] and that the symptoms are associated with poor well-being and depression, especially in women [16].

The economic burden of post-stroke LUTS on the healthcare service is high because the symptoms often require life-long medical care [17]. Indirect cost as pads,

*Corresponding author: Sigrid Tibaek, PT, DMSc, Department of Occupational Therapy and Physiotherapy, Rigshospitalet, University of Copenhagen, Valdemar Hansens Vej 13, DK- 2600 Glostrup, Denmark, Tel: +45-43-682793, Fax: 38-63-39-13

Accepted: September 20, 2018; Published online: September 22, 2018

Citation: Tibaek S (2018) The Role of Physiotherapy in the Rehabilitation of Stroke Patients with Lower Urinary Tract Symptoms. J Phys Med 1(1):32-40

Copyright: (C) 2018 Tibaek S. This is an open-access article distributed under the terms of the Creative Commons Attribution License, which permits unrestricted use, distribution, and reproduction in any medium, provided the original author and source are credited. 
Citation: Tibaek S (2018) The Role of Physiotherapy in the Rehabilitation of Stroke Patients with Lower Urinary Tract Symptoms. J Phys Med 1(1):32-40

Table 1: Definitions of some Lower Urinary Tract Symptoms (LUTS).

\begin{tabular}{|c|c|}
\hline Symptoms & Definition \\
\hline Nocturia & - Is the complaint that the individual has to wake at night one or more times to void \\
\hline Urgency & - Is the complaint of a sudden compelling desire to pass urine, which is difficult to defer \\
\hline Increased daytime frequency & - Is the complaint by the patient who considers that he/she voids too often by day \\
\hline Urinary incontinence & - Is the complaint of any involuntary leakage of urine \\
\hline \multicolumn{2}{|l|}{ Types of urinary incontinence } \\
\hline Stress & $\begin{array}{l}\text { - Is the complaint of involuntary leakage on effort or exertion, or on sneezing or on } \\
\text { coughing }\end{array}$ \\
\hline Urge & $\begin{array}{l}\text { - Is the complaint of involuntary leakage accompanied by or immediately preceded by } \\
\text { urgency }\end{array}$ \\
\hline Mixed stress/urge & $\begin{array}{l}\text { - Is the complaint of involuntary leakage associated with urgency and also with exertion, } \\
\text { effort, sneezing or coughing }\end{array}$ \\
\hline $\begin{array}{l}\text { Feeling of incomplete bladder } \\
\text { emptying }\end{array}$ & - Is a self-explanatory term for a feeling experiences by the individual after passing urine \\
\hline Post micturition dribble & $\begin{array}{l}\text { - Is the term when an individual describes the involuntary loss of urine immediately after } \\
\text { has finished passing urine, usually after leaving the toilet in men, or after rising from toilet } \\
\text { in women }\end{array}$ \\
\hline
\end{tabular}

Reference: Abrams, et al. [4]; Abrams, et al. [5].

medicines, washing/clothes and time taken by health professionals are the most expensive elements. Loss of productive time is also important for health professionals, caregivers and relatives. Moreover, for the stroke patients who need constant assistance in bladder activities expensive institutionalisation is necessary $[18,19]$.

Several studies have reported that post-stroke LUTS is most prevalent in the acute phase [20,21]. Most UTIS occur after 48 hours and are hospital-acquired associated with urinary catheterisation $(\mathrm{OR}=3.03)$ [22]. UTI $(10)$, UI [23] and urine retention [24] have signifikant imports on stroke rehabilitation due to prolonged hospital stays [25]. Elder, et al. reported that post-stroke patients with UI lost $24 \%$ of their rehabilitation time through UI-related problems [26]. According to Pettersen, et al. poststroke UI is a strong predictor for decreased level of physical recovery [27].

Multidisciplinary teams made up of medical doctors, nurses, physiotherapists (PTs) and occupational therapists perform stroke rehabilitation in all phases and settings such as hospitals, communities and clinics. Jia, et al. showed that physiotherapy and occupational therapy were the most common treatment in stroke rehabilitation in the USA [28].

Traditionally, PTs focus largely on motor function such as sitting, standing and walking, while the nurses and doctors have primary responsibility for LUTS.

The International Continence Society (ICS) guidelines for treating UI in frail older adults' emphases the importance of maximising toileting ability by combining conservative training for bladder leakage with activities that improve physical function [29]. Therefore, potential elements of prevention and treatment programmes may include physical activity to maintain or improve toileting skills and conservative training i.e., pelvic floor muscle training (PFMT).

The aims in terms of LUTS for PT in stroke rehabilitation are to: a) Prevent LUTS, b) Achieve or maintain urinary continence, c) Recover of LUTS and d) Improve QoL. Further considerations are the patient's disability and possible complications.

In the mid-1990s the first randomised controlled trials (RCTs) were published indicating the effect of PFMT in neurologically healthy women and men with LUTS $[30,31]$.

Positive effects have also been identified for PFMT on LUTS in patients with neurological diseases [32-34]. In women with UI after their first stroke. Twelve weeks of PFMT leads to significant reduction in UI leakage and frequency of voiding $[34,35]$. Likewise, in post-stroke men with LUTS 12 weeks of PFMT indicated benefits for LUTS, erectile dysfunction and QoL [36-38]. No adverse events have been reported during PFMT programmes [36].

Not only are post-stroke LUTS under-diagnosed but there is also evidence suggesting under-treated $[39,40]$. Reports indicate that among neurologically healthy women with UI fewer than $50 \%$ seek care due to a range of barriers including lack of knowledge of treatment possibilities [41]. That proportion is likely to be higher in post-stroke patients with LUTS because neurologically healthy patients demonstrate more resources and knowledge about UI treatment compared with women with neurologic diseases. However, it is unclear if there are additional barriers in post-stroke patients, which contribute to a variation regarding seeking care.

Despite the high prevalence of LUTS in post-stroke patients, its major impact on QoL and increased PT 
Citation: Tibaek S (2018) The Role of Physiotherapy in the Rehabilitation of Stroke Patients with Lower Urinary Tract Symptoms. J Phys Med 1(1):32-40

treatment research, there seems to be little attention paid to, and knowledge gained about what $\mathrm{PT}$ can provide in the rehabilitation of post-stroke patients with LUTS [42].

The objective of this study is to describe how PT in rehabilitation can be involved in the prevention, diagnostic and treatment of post-stroke patients with LUTS.

\section{Neuropathology}

The bladder performs two functions, storage and emptying. The neural control of these functions is done by neural programs, which are located within the pons. The switch between these functions are influence by the suprapontine. Micturition frequency in healthy adults with bladder capacity of $500 \mathrm{ml}$ is typically about once every 3-4 hours, depending on fluid intake. Since the act of voiding takes 2-3 minutes, for $98-99 \%$ of the time the bladder is in storage mode [43]. In the healthy and continent state when to void is determined by the perceived state of bladder fullness together with an assessment of social appropriateness to do so [43].

To affect both storage and voiding, connections between the pons and the sacral spinal cord must be intact as well as the peripheral innervation arising from the pelvic and the pudendal nerves to innervate the bladder and the internal and external sphincter muscles. Thus, the innervation needed for physiological bladder control is extensive requiring suprapontine imputes. Intact spinal connections between the pons and the sacral cord, as well as intact peripheral nerves [44].

Pathophysiology changes after stroke are complex and only partially understood as suggested by Andrew and Nathan [44]. The authors suggested that the antero-medial region in the frontal lobe was aeriated with the control of micturition [45]. A lesion in the other parts of the brain leads to UI which is probably due to the disruption of the pathways between the higher centres and the pontine micturition centre $[46,47]$.

Interference of these pathways would be expected to lead to loss of higher cerebral inhibition of detrusor reflex activity and hence to an overactive bladder.

Borrie performed systematic tests in 22 acute stroke patients with moderate to severe UI that had persisted for weeks post-stroke [48].

Detrusor instability was present in $85 \%$ of those who had been continent pre-stroke and a further two patients showed SUI while two others showed urinary retention [48].

Gelber carried out urodynamic studies in 19 poststroke patients with UI. Bladder overactivity was persistent in $37 \%$ of the group, bladder atomicity in $21 \%$, detrusor-sphincter dyssynergia in 5\%, leaving $37 \%$ with normal bladder function [49].

Nazarko reported that stroke survivors whom are aware of bladder fullness but cannot inhibit bladder contraction experience LUTS such as frequency, urgency and possible urge urinary incontinence (UUI) [50].

Petersen, et al. explained that the disruption of neuromicturition pathways can lead to an impaired awareness of the need to void even in cognitively intact stoke patients [27].

Fowler, et al. showed that the human lower urinary tract is controlled by a complex supraspinal network [51]. More recently a growing number of functional neuroimaging studies have investigated supraspinal control of urinary tract control during bladder filling and pelvic floor muscle (PFM) contractions. According to Michels, et al. little is known about the supraspinal areas and dynamic processes involving micturition and the voluntary switch over "that is often impaired in patients with LUTS" [52].

Neuroimaging studies include healthy individuals, whereas no such studies have been done for stroke patients with LUTS.

\section{Prevention}

Regarding physical function, several factors may be considered for their role in preventing LUTS during stroke rehabilitation.

Optimal bladder emptying is an important factor in preventing UTI. Therefore, if possible, at each micturition the patients need mobilisation to the sitting or standing position. Neither healthy nor non-healthy people can empty their bladder when lying down $[53,54]$.

Another factor preventing UTI relates to stroke patients who are able to clean themselves after micturition. Some patients have to be educated on the preferred cleaning movement of front to back, to avoid the risk of coli bacteria near the urinary tract opening.

\section{Environmental factors}

The PTs, together with the rehabilitation team, may consider prevention factors in the varieties of physical environments the stroke patients live in. Particularly for stroke patients suffering nocturia. A key question is: How can the patient safety get to the toilet at night? Is the toilet sign posted? Is there optimal lighting? Do the patients have safe shoes and clothes suitable for fast dressing? In addition, is there free access without e.g., loose blankets? Is the bathroom floor dry? Are there toilet grabs bars and can the height of the toilet seat be adjusted [55]? Further considerations, for post-stroke patients with LUTS includes and impaired vision need special care. Moreover, there is significant association between LUTS and risk of 
Citation: Tibaek S (2018) The Role of Physiotherapy in the Rehabilitation of Stroke Patients with Lower Urinary Tract Symptoms. J Phys Med 1(1):32-40

falls in stroke patients [56-60].

Due to hygiene or cultural issues, some patients, avoid sitting down, when crouching or hovering over the toilet. Consequently, the PFM cannot relax which sometimes leads to incomplete bladder emptying of urine $[61,62]$.

Cognitive impairment may complicate the effect of prevention and treatment in post-stroke patients, as patients may have limited understanding and recall, and have misconceptions about their symptoms. However, it is standard to screen for cognitive impairment in stroke patients.

Epidemiological studies in toileting-related disabilities of stroke patients are needed.

\section{Assessments}

\section{LUTS}

Bladder scan by ultrasound is used to detect for urine retention, and test of urine for leucocytes, nitrites, glucose and protein, both of which are basic nursing assessments completed within the first 24 hours of admission [63]. During rehabilitation, PTs can use other assessments depending on the stroke severity.

Frequency/volume charts, recorded over at least three days, detect the frequency and volume of fluid intake and urine output. Additionally, a simple bladder diary recording time and frequency of micturition and the number of UI episodes can be useful [34,37].

Previously, a subscale in the Barthel Index has been used as a measure of UI in stroke patients but the Danish Prostate Symptom Score (DAN-PSS-1) questionnaire [64] (Table 2) has been suggested as a more specific instrument [16].

The DAN-PSS-1 questionnaire is a patient-reported measure consisting of 12 items, which detects LUTS, its severity, and, for each symptom, its impact on daily life. The DAN-PSS-1 questionnaire has acceptable validity and reliability in post-stroke men and women $[34,65,66]$.

For treatment, appropriate assessment is essential. Therefore, assessment of the pelvic floor muscle (PFM) function is important. PTs with specialised education can evaluate the PFM function, strength, and static and dynamic endurance by digital vaginal palpation in women and digital anal palpation in men $[67,68]$.

The assessor evaluates whether the patient can perform an isolated PFM contraction or use associated muscles e.g. abdominal muscles, $\mathrm{m}$. adductor femoris and $\mathrm{m}$. gluteus max.

After feed-back to the patients, the PFM strength can be evaluated using the modified Oxford Scale (0-5 score for women and 0-6 for men). Static contraction is especially important in stroke patients due to cardiovascular disease as stroke and last the dynamic contraction again due to the cardiovascular basic cause. For ethical reasons, it is recommended that patients' signup for appointment when they want to be PFM evaluated.

Other specific assessments for evaluation of the PFM, such as perineometer and electromyography, have also been reported in female stroke patients [35].

\section{Mobility}

Mobilisation is the key factor for independent toilet visits. The term toilet disability, defined as "having difficulty with or requiring human or mechanical assistance with toileting" [69], has mostly been studied as a subscale of activity of daily living (ADL) assessments. Furthermore, the Functional Independence Measure (FIM) is available particularly as a basic physiotherapy assessment regarding a chain of physical functions such as a) Transfers (from/to bed, chair or wheelchair and toilet),

Table 2: The Danish Prostate Symptom Score (DAN-PSS-1) Questionnaire. (Brasso, et al, 1994 (64)).

\section{Hesitancy: Do you have to wait for urination to start?}

2. Decreased stream: Is your urinary stream weak or dribbling?

3. Incomplete emptying: Do you feel you empty your bladder completely?

4. Straining: Do you have to strain to start and/or maintain urination?

5. Daytime frequency: What is the longest interval between each urination, from when you wake up until you go to bed?

6. Nocturnal urination: How many times do you have to urinate during the night?

7. Urge: Do you experience an imperative (strong) urge to urinate?

8. Urge incontinence: Is the urge to urinate to strong that urine starts to flow before you reach the toilet?

9. Dysuria: Does it hurt or burn when you urinate?

10. Terminal dribbling: Do you experience dribbling after voiding, when you feel you have finished urination?

11. Stress incontinence: Do you experience leakage of urine when physically active (e.g. lighting, sneezing, coughing)?

12. Other incontinence: Do you experience leakage without urge or physical activity? 
Citation: Tibaek S (2018) The Role of Physiotherapy in the Rehabilitation of Stroke Patients with Lower Urinary Tract Symptoms. J Phys Med 1(1):32-40

b) Locomotion (walking or wheelchair, c) Dress on/off lower body, d) Maintaining a proper position, e) Managing bladder outlet and f) Personal hygiene [70].

If possible, it is important to educate post-stroke patients with urgency and UUI to express their desire for micturition as soon as it is felt. More specific assessment of walking distance and speed are essential elements for stroke patients with urgency and UUI aiming to enable them to reach a toilet quickly [7]. A similar assessment is required for stroke patients with impaired upper-extremity for their ability to reach and grasp as part of the cleaning function after micturition.

\section{Treatment}

PFMT can be used as first-line conservative treatment for men and women with post-stroke LUTS [34-37,71]. However, the treatment has to be provided at all levels (I-III) depending on the severity of the stroke and on PTs' understanding of LUTS [72].

In level I, the stroke patient can be educated about the prevalence and possible duration of LUTS, the most common LUTS and their definitions or characteristics, and their impact on physical, social and mental health.

Regarding PFM function, information to be important includes PFM localisation, PFM function, PFM extent in women and men, awareness of PFM contraction and relaxation, ending with instruction in PFM exercises. PFM models illustrated all, by models and pictures.

The treatment at level II, based on increase awareness of PFM function, includes information, instruction and training in "the Knack" manoeuvre. which is a voluntarily PFM contraction before and during laughing, coughing, sneezings [73] and functional tasks e.g. standing up, sitting down or walking [36]. When the stroke patient expresses awareness of some PFM contraction he/she is recommended to perform the manoeuvre during each relevant functional task.

At level III, the PFMT has to be planned according to the results of the PFM assessment. The assessment must be performed at least as Pre-test and Post-test, but also during the training period giving feed-back to the patient and following the PFM progression. The PFMT can be performed individually or in small groups, supervised by a specialist PT $[34,37]$. The supervising PT is important in term of motivation for adherence to the training, increasing the training effort [74], and avoiding activity in the $\mathrm{m}$. abdominals, $\mathrm{m}$. gluteus max and $\mathrm{m}$. adductor femoris, and guiding functional visualisation tasks training.

The PFMT programmer includes theory, PFM function and strength, and particularly the static and dynamic endurance due to cardiovascular diseases such as stroke, and visualised PFM contraction during functions tasks (the Knack manoeuvre) due to e.g., urgency, in which the stroke patients hurries to a toilet.

The home exercises programme must be progressive implies continuous progressive according to the PFM status with a training frequency of at least three times a week for 12 weeks.

For men with post-micturition urine leakage, instruction in three to four powerful PFM contractions has been reported to be beneficial [75].

\section{Information for relatives}

The PTs play an important role in some cases in informing relatives about LUTS: concerning a) What to do in regard to prevention, b) What to do concerning treatment, and c) Where to seek help in the health care system.

\section{Discussion}

This study describes how physiotherapy can be involved in the rehabilitation of post-stroke patients with LUTS. Factors for prevention of LUTS are identified, validated and reliable assessments are presented; and treatment of PFM at different levels is reported. However, low numbers of studies and small sample sizes limits the evidence.

\section{Prevention}

Urgency and nocturia in older people are strongly associated with falls. The cause has been discussed but, according to Gibson, et al., the reason remains to be explored [60]. The cause of urgency and UUI in post-stroke patients has been explained by brain injury. Whether a risk of cardiovascular events could be associated in older people is unclear [76].

Impaired micturition is defined as "the inability to void, despite having the urge to do so", and in post percutaneous coronary intervention (PCI) patients it has been reported that modified spine position could facilitate bladder emptying. The bed was tilted by $20^{\circ}$ with a pillow between the feet. The results indicated that patients in the intervention group had significantly better bladder emptying and shorter time to void post PCI [53].

Whether this intervention facilitates prevention of urinary cauterisation in post-stroke patients with problems of bladder emptying, due to their ethology is unknown. Impaired micturition may also lead to nephropathy.

\section{Assessments}

In a study by Stineman, et al. stroke patients undergoing acute rehabilitation preferred early recovery of the 
Citation: Tibaek S (2018) The Role of Physiotherapy in the Rehabilitation of Stroke Patients with Lower Urinary Tract Symptoms. J Phys Med 1(1):32-40

ability to eat and control their bowel and bladder functions over recovery of cognition and communication [77].

A Web-based Toileting Behaviour instrument has been developed and validated, aiming to access and understands toileting behaviour in women with non-neurological conditions [78]. This instrument might be useful in screening for some post-stroke patients.

\section{Treatment}

In a review of therapeutic education for post-stroke patients, Daviet, et al. reported that a nurse-targeted education programme might improve longer term continence [79]. However, the most severe stroke patients may have limited ability to participate in some of the more demanding therapies.

In the study by Shin, et al. the frequency of supervised PFMT was three times per week for six weeks compared with the studies by Tibaek, et al. [34-37,71] once a week for 12 weeks combined with progressive home exercise programme for daily training.

Recently, studies suggest that increase in amount of standard rehabilitation leads to better outcomes for people living with the disabling consequences of strokes [8082].

During rehabilitation, PTs need to consider the stroke patient. Nevertheless, there seem to be several barriers regarding patients with post-stroke LUTS. Dumoulin, et al. reported, in a study of stroke rehabilitation professionals, a lack of knowledge in the field of UI and the need for UI strategies in the health service organisation [42].

Several other barriers may influence PTs' attitudes such as time and resources are not attitudes, in the intervention, practical and environmental factors.

\section{Methodological considerations}

The main limitation in this study is the lack of a systematic review. However, its aims were to describe, not to investigate, how physiotherapy can be involved in the rehabilitation of post-stroke patients with LUTS.

\section{Perspective}

PFMT has the potential to benefit post-stroke patients with LUTS. Other non-invasive treatments, such as neuromodulation performed by the posterior tibialis stimulation nerve, have given reported benefits for men [83]. For post-stroke patients with LUTS and impaired mobility, the potential of technical devices such as toilet-assistance machines, aiming to clean and take off and replace trousers, leads to independent toilet behaviour. However, these approaches all have to be based on appropriate as- sessment in terms of LUTS and the patient's ability.

Confidence and great respect are important contributions to beneficial treatment, particularly in post-stroke patients with symptoms as LUTS. Most PTs already have these competences, through experience, careful clinical planning and training in the rehabilitation of individual stroke patients.

Further research should seek to develop specific LUTS assessments, identify preventing factors and improve the effect of treatment.

\section{Conclusions}

This paper attempts to contribute more comprehensive knowledge for understanding LUTS and to improve QoL in post-stroke patients with the condition. However, the evidence is still limited by the paucity of studies and small sample sizes.

It is recommended that PTs, through their central role in the rehabilitation of stroke patients, contribute with their specific knowledge to the prevention, diagnostic and treatment of post-stroke patients with LUTS.

\section{References}

1. Feigin VL, Lawes CM, Bennett DA, et al. (2009) Worldwide stroke incidence and early case fatality reported in 56 population-based studies: a systematic review. Lancet Neurol 8: 355-369.

2. Billinger SA, Arena R, Bernhardt J, et al. (2014) Physical activity and exercise recommendations for stroke survivors: a statement for healthcare professionals from the American Heart Association/American Stroke Association. Stroke 45: 2532-2553.

3. Murray CJ, Vos T, Lozano R, et al. (2012) Disability-adjusted life years (DALYs) for 291 diseases and injuries in 21 regions, 1990-2010: a systematic analysis for the Global Burden of Disease Study 2010. Lancet 380: 2197-2223.

4. Abrams P, Cardozo L, Fall M, et al. (2002) The Standardisation of Terminology of Lower Urinary Tract Function: Report from the Standardisation Sub-committee of the International Continence Society. Neurourol Urodyn 21: 167-178.

5. Abrams P, Cardozo L, Fall M, et al. (2003) The standardisation of terminology in lower urinary tract function: report from the standardisation sub-committee of the International Continence Society. Urology 61: 37-49.

6. Abrams P, Artibani W, Cardozo L, et al. (2009) Reviewing the ICS 2002 terminology report: the ongoing debate. Neurourol Urodyn 28: 287.

7. Tibaek S, Gard G, Klarskov P, et al. (2008) Prevalence of lower urinary tract symptoms (LUTS) in stroke patients: a cross-sectional, clinical survey. Neurourol Urodyn 27: 763-771.

8. Williams MP, Srikanth V, Bird M, et al. (2012) Urinary symptoms and natural history of urinary continence after first-ever stroke--a longitudinal population-based study. Age Ageing 41: 371-376.

9. Wu J, Baguley IJ (2005) Urinary retention in a general reha- 
Citation: Tibaek S (2018) The Role of Physiotherapy in the Rehabilitation of Stroke Patients with Lower Urinary Tract Symptoms. J Phys Med 1(1):32-40

bilitation unit: prevalence, clinical outcome, and the role of screening. Arch Phys Med Rehabil 86: 1772-1777.

10. Westendorp WF, Nederkoorn PJ, Vermeij JD, et al. (2011) Post-stroke infection: a systematic review and meta-analysis. BMC Neurol 11: 110.

11. Edwards DF, Hahn M, Dromerick A (2006) Post stroke urinary loss, incontinence and life satisfaction: when does post-stroke urinary loss become incontinence? Neurourol Urodyn 25: 39-45.

12. Brittain KR, Shaw C (2007) The social consequences of living with and dealing with incontinence--a carers perspective. Soc Sci Med 65: 1274-1283.

13. Franceschini M, La Porta F, Agosti M, et al. (2010) Is health-related-quality of life of stroke patients influenced by neurological impairments at one year after stroke? Eur $\mathrm{J}$ Phys Rehabil Med 46: 389-399.

14. Itoh Y, Yamada S, Konoeda F, et al. (2013) Burden of overactive bladder symptom on quality of life in stroke patients. Neurourol Urodyn 32: 428-434.

15. Tseng CN, Huang GS, Yu PJ, et al. (2015) A Qualitative Study of Family Caregiver Experiences of Managing Incontinence in Stroke Survivors. PLoS One 10: e0129540.

16. Tibaek S, Dehlendorff C, Iversen HK, et al. (2011) Is well-being associated with lower urinary tract symptoms in patients with stroke? Scand J Urol Nephrol 45: 134-142.

17. Groen J, Pannek J, Castro Diaz D, et al. (2016) Summary of European Association of Urology (EAU) Guidelines on Neuro-Urology. Eur Urol 69: 324-333.

18. Kolominski-Rabas P, Hilz MJ, Neundoerfer B, et al. (2003) Impact of urinary incontinence after stroke: Results from a prospective population-basted study register. Neurourol Urodyn 22: 322-327.

19. Patel M, Coshall C, Rudd AG, et al. (2001) Natural history and effects on 2-year outcomes of urinary incontinence after stroke. Stroke 32: 122-127.

20. Thomas LH, Cross S, Barrett J, et al. (2008) Treatment of urinary incontinence after stroke in adults. Cochrane Database Syst Rev 23: CD004462.

21. Cournan M (2012) Bladder management in female stroke survivors: translating research into practice. Rehabil Nurs 37: $220-230$.

22. Stott DJ, Falconer A, Miller $\mathrm{H}$, et al. (2009) Urinary tract infection after stroke. QJM 102: 243-249.

23. Curtis LA, Dolan TS, Cespedes RD (2001) Acute urinary retention and urinary incontinence. Emerg Med Clin North Am 19: 591-619.

24. Mustonen S, Ala-Houhala IO, Tammela TL (2001) Longterm renal dysfunction in patients with acute urinary retention. Scand J Urol Nephrol 35: 44-48.

25. Vermeij FH, Scholte op Reimer WJ, de Man P, et al. (2009) Stroke-associated infection is an independent risk factor for poor outcome after acute ischemic stroke: data from the Netherlands Stroke Survey. Cerebrovasc Dis 27: 465-471.

26. Elder R, Ring H, Tshuwa M, et al. (2001) Quality of care on urinary incontinence in a rehabilitation setting for patients with Stroke. Simultaneous monitoring of process and outcome. Int J Health Care 13: 57-61.
27. Pettersen R, Wyller TB (2006) Prognostic significance of micturition disturbances after acute stroke. J Am Geriatr Soc 54: 1878-1884.

28. Jia H, Pei Q, Sullivan CT, et al. (2017) Regional variation in post-stroke multidisciplinary rehabilitation care among veteran residents in community nursing homes. J Multidiscip Healthc 10: 75-85.

29. Abrams P, Andersson KE, Birder L, et al. (2010) Fourth International Consultation on Incontinence Recommendations of the International Scientific Committee: Evaluation and treatment of urinary incontinence, pelvic organ prolapse and fecal incontinence. Neurourol Urodyn 29: 213-240.

30. Moore KN, GF Dorey (1999) Conservative Treatment of Urinary Incontinence in Men. A review of the literature. Physiotherapy 85: 77-87.

31. Bø K (1990) Pelvic floor muscle exercise for treatment of female stress urinary incontinence. Methodological studies and clinical results. Doctoral thesis. Oslo: The Norvegian University of sport and physical education.

32. De Ridder D, Vermeulen C, Ketelaer P, et al. (1999) Pelvic floor rehabilitation in multiple sclerosis. Acta Neurol Belg 99: 61-64.

33. Lucio A, D'Ancona C, Lopes M, et al. (2014) The effect of pelvic floor muscle training alone or in combination with electrostimulation in the treatment of sexual dysfunction in women with multiple sclerosis. Mult Scler 20: 1760-1768.

34. Tibaek S, Gard G, Jensen R (2005) Pelvic floor muscle training is effective in women with urinary incontinence after stroke. Neurourol Urodyn 24: 348-357.

35. Shin DC, Shin SH, Lee MM, et al. (2016) Pelvic floor muscle training for urinary incontinence in female stroke patients: a randomized, controlled and blinded trial. Clin Rehabil 30: 259-267.

36. Tibaek S, Gard G, Dehlendorff C, et al. (2015) The effect of pelvic floor muscle training on sexual function in men with lower urinary tract symptoms after stroke. Top Stroke Rehabil 22: 185-193.

37. Tibaek S, Gard G, Dehlendorff C, et al. (2017) Is Pelvic Floor Muscle Training Effective for Men With Poststroke Lower Urinary Tract Symptoms? A Single-Blinded Randomized, Controlled Trial. Am J Mens Health 11: 1460-1471.

38. Tibaek S, Gard G, Dehlendorff C, et al. (2017) Lower Urinary Tract Symptoms, Erectile Dysfunction, and Quality of Life in Poststroke Men: A Controlled Cross-Sectional Study. Am J Mens Health 11: 748-756.

39. Booth J, Kumlien S, Zang Y, et al. (2009) Rehabilitation nurses practices in relation to urinary incontinence following stroke: a cross-cultural comparison. J Clin Nurs 18: 1049-1058.

40. Party ISW (2012) National clinical guideline for stroke, $\left(4^{\text {th }}\right.$ edn), Royal College of Physicians, UK.

41. Schreiber Pedersen L, Lose G, Høybye MT, et al. (2018) Predictors and reasons for help-seeking behavior among women with urinary incontinence. Int Urogynecol J 29: 521-530.

42. Dumoulin C, Korner-Bitensky N, Tannenbaum C (2005) Urinary incontinence after stroke: does rehabilitation make a difference? A systematic review of the effectiveness of behavioral therapy. Top Stroke Rehabil 12: 66-76. 
Citation: Tibaek S (2018) The Role of Physiotherapy in the Rehabilitation of Stroke Patients with Lower Urinary Tract Symptoms. J Phys Med 1(1):32-40

43. Lukacz ES, Sampselle C, Gray M, et al. (2011) A healthy bladder: a consensus statement. Int J Clin Pract 65: 1026-1036.

44. Fowler CJ (1999) Neurological disorders of micturition and their treatment. Brain 122: 1213-1231.

45. Andrew J, Nathan PW (1964) Lesions On The Anterior Frontal Lobes And Disturbances Of Micturition And Defaecation. Brain 87: 233-262.

46. Brittain KR, Peet SM, Castleden CM (1998) Stroke and incontinence. Stroke 29: 524-528.

47. Brittain KR, Peet SM, Potter JF, et al. (1999) Prevalence and management of urinary incontinence in stroke survivors. Age Ageing 28: 509-511.

48. Borrie MJ (1998) Increased incontinence after stroke. In: Teasell RW, Stroke Rehabilitation Physical Medicine and Rehabilitation State of the Art Reviews. 12. Hanley and Belfus, Philadelphia, 457-459.

49. Gelber DA, Good DC, Laven LJ, et al. (1993) Causes of urinary incontinence after acute hemispheric stroke. Stroke 24: 378-382.

50. Nazarko L (2003) Rehabilitation and continence promotion following a stroke. Nurs Times 99: 52.

51. Fowler CJ, Griffiths D, de Groat WC (2008) The neural control of micturition. Nat Rev Neurosci 9: 453-466.

52. Michels L, Blok BF, Gregorini F, et al. (2015) Supraspinal Control of Urine Storage and Micturition in Men--An fMRI Study. Cereb Cortex 25: 3369-3380.

53. Liu Y, Zhang Y, Wu Y, et al. (2018) A Modified Supine Position Facilitates Bladder Function in Patients Undergoing Percutaneous Coronary Intervention: A Randomized Controlled Clinical Trial. J Cardiovasc Nurs 33: 152-159.

54. Choi S, Awad I (2013) Maintaining micturition in the perioperative period: strategies to avoid urinary retention. Curr Opin Anaesthesiol 26: 361-367.

55. Kennedy MJ, Arcelus A, Guitard P, et al. (2015) Toilet Grab-Bar Preference and Center of Pressure Deviation During Toilet Transfers in Healthy Seniors, Seniors With Hip Replacements, and Seniors Having Suffered a Stroke. Assist Technol 27: 78-87.

56. Jørgensen L, Engstad T, Jacobsen BK (2002) Higher incidence of falls in long-term stroke survivors than in population controls: depressive symptoms predict falls after stroke. Stroke 33: 542-547.

57. Lamb SE, Ferrucci L, Volapto S, et al. (2003) Risk factors for falling in home-dwelling older women with stroke: the Women's Health and Aging Study. Stroke 34: 494-501.

58. Nyberg L, Gustafson $Y$ (1997) Fall prediction index for patients in stroke rehabilitation. Stroke 28: 716-721.

59. Divani AA, Vazquez G, Barrett AM, et al. (2009) Risk factors associated with injury attributable to falling among elderly population with history of stroke. Stroke 40: 3286-3292.

60. Gibson W, Hunter KF, Camicioli R, et al. (2018) The association between lower urinary tract symptoms and falls: Forming a theoretical model for a research agenda. Neurourol Urodyn 37: 501-509.

61. Moore KH, Richmond DH, Sutherst JR, et al. (1991) Crouching over the toilet seat: prevalence among British gynaecological outpatients and its effect upon micturition. Br J Obstet Gynaecol 98: 569-572.

62. Unsal A, Cimentepe E (2004) Voiding position does not affect uroflowmetric parameters and post-void residual urine volume in healthy volunteers. Scand J Urol Nephrol 38: 469-471.

63. Fisher AR (2014) Development of clinical practice guidelines for urinary continence care of adult stroke survivors in acute and rehabilitation settings. Can $\mathrm{J}$ Neurosci Nurs 36: 16-31.

64. Brasso K, Stigsby B, Pilsgård B, et al. (1994) Precision of a patient-weighted symptom score in prostatism. The DANPSS-1 questionnaire. Scand J Urol Nephrol 28: 71-75.

65. Tibaek S, Gard G, Klarskov P, et al. (2009) Are activity limitations associated with lower urinary tract symptoms in stroke patients? A cross-sectional, clinical survey. Scand J Urol Nephrol 43: 383-389.

66. Yesil H, Akkoc Y, Karapolat H, et al. (2017) Reliability and validity of the Turkish version of the Danish Prostatic Symptom Score to assess lower urinary tract symptoms in stroke patients. NeuroRehabilitation 41: 429-435.

67. Laycock J (1994) Pelvic muscle exercises: physiotherapy for the pelvic floor. Urol Nurs 14: 136-140.

68. Tibaek S, Gard G, Dehlendorff C, et al. (2016) Can pelvic floor muscle training improve quality of life in men with mild to moderate post-stroke and lower urinary tract symptoms? A randomised, controlled and single-blinded trial. Eur $\mathrm{J}$ Phys Rehabil Med 2016.

69. Talley KM, Wyman JF, Bronas UG, et al. (2014) Factors associated with toileting disability in older adults without dementia living in residential care facilities. Nurs Res 63: 94-104.

70. Whiteneck GG, Charlifue SW, Gerhart KA, et al. (1992) Quantifying handicap: a new measure of long-term rehabilitation outcomes. Arch Phys Med Rehabil 73: 519-526.

71. Tibaek S, Gard G, Dehlendorff C, et al. (2017) Can pelvic floor muscle training improve quality of life in men with mild to moderate poststroke and lower urinary tract symptoms? Eur J Phys Rehabil Med 53: 416-425.

72. Dumoulin C, Korner-Bitensky N, Tannenbaum C (2007) Urinary incontinence after stroke: identification, assessment, and intervention by rehabilitation professionals in Canada. Stroke 38: 2745-2751.

73. Miller JM, Sampselle C, Ashton-Miller J, et al. (2008) Clarification and confirmation of the Knack maneuver: the effect of volitional pelvic floor muscle contraction to preempt expected stress incontinence. Int Urogynecol J Pelvic Floor Dysfunct 19: 773-782.

74. Kim EY, Kim SY, Oh DW (2012) Pelvic floor muscle exercises utilizing trunk stabilization for treating postpartum urinary incontinence: randomized controlled pilot trial of supervised versus unsupervised training. Clin Rehabil 26: 132-141.

75. Dorey G (2008) Post-micturition dribble: aetiology and treatment. Nurs Times 104: 46-47.

76. Lin HJ, Weng SF, Yang CM, et al. (2013) Risk of hospitalization for acute cardiovascular events among subjects with lower urinary tract symptoms: a nationwide population-based study. PLoS One 8: e66661. 
Citation: Tibaek S (2018) The Role of Physiotherapy in the Rehabilitation of Stroke Patients with Lower Urinary Tract Symptoms. J Phys Med 1(1):32-40

77. Stineman MG, Rist PM, Kurichi JE, et al. (2009) Disability meanings according to patients and clinicians: imagined recovery choice pathways. Qual Life Res 18: 389-398.

78. Wang K, Palmer MH (2011) Development and validation of an instrument to assess women's toileting behavior related to urinary elimination: preliminary results. Nurs Res 60: 158-164.

79. Daviet JC, Bonan I, Caire JM, et al. (2012) Therapeutic patient education for stroke survivors: Non-pharmacological management. A literature review. Ann Phys Rehabil Med 55: 641-656.

80. Schneider EJ, Lannin NA, Ada L, et al. (2016) Increasing the amount of usual rehabilitation improves activity after stroke: a systematic review. J Physiother 62: 182-187.

81. Lang CE, Lohse KR, Birkenmeier RL (2015) Dose and timing in neurorehabilitation: prescribing motor therapy after stroke. Curr Opin Neurol 28: 549-555.

82. Lohse KR, Lang CE, Boyd LA (2014) Is more better? Using metadata to explore dose-response relationships in stroke rehabilitation. Stroke 45: 2053-2058.

83. Monteiro ÉS, de Carvalho LB, Fukujima MM, et al. (2014) Electrical stimulation of the posterior tibialis nerve improves symptoms of poststroke neurogenic overactive bladder in men: a randomized controlled trial. Urology 84: 509-514. 